\title{
INFLUENCE OF PROBIOTICS ON Candida PRESENCE AND IgA ANTI-Candida IN THE ORAL CAVITY
}

\author{
Agda Lima dos Santos*; Antônio Olavo Cardoso Jorge; Silvana Soléo Ferreira dos Santos; \\ Célia Regina Gonçalves e Silva; Mariella Vieira Pereira Leão
}

Instituto Básico de Biociências, Universidade de Taubaté, Taubaté, SP, Brasil

Submitted: September 15, 2008; Returned to authors for corrections: April 09, 2009; Approved: June 28, 2009.

\begin{abstract}
Probiotics are defined as microorganisms that promote benefits to host health, mainly by regulating resident microbiota. Disequilibrium in microbiota can favor the growth of opportunist microorganisms and the development of pathologies, like candidosis caused by yeasts of the Candida genus. This work evaluated whether probiotics consumption was able to influence a specific immunological response to Candida and the presence of these yeasts in the oral cavity. Saliva samples were collected from healthy individuals and plated in Dextrose Saboraud Agar with chloramphenicol. Individuals presenting Candida in the oral cavity used the probiotic Yakult $\mathrm{LB} \otimes$ for 20 days, after which new collections and identifications were performed. Anti-Candida IgA analysis was conducted using the ELISA technique. Analysis of the results showed a significant reduction in Candida prevalence (46\%) and mean Candida CFU/mL counts (65\%). The Candida species identified were C. albicans (98\%) and C. tropicalis (2\%), before and after probiotics consumption. Immunological analysis demonstrated a significant reduction in anti-Candida IgA levels after probiotics use, probably due to less antigenic stimulation. In conclusion, in the individuals studied, probiotics use significantly reduced the amount of Candida in the oral cavity, possibly due to competition between the yeasts rather than by specific secretory immune response stimulation.
\end{abstract}

Key words: Candida; IgA; Lactobacillus casei; Bifidobacterium

\section{INTRODUCTION}

Probiotics are defined as microorganisms that promote benefits to host health, principally by means of resident microbiota regulation (4). The presence of probiotic microorganisms in intestinal mucosa can prevent the colonization of pathogens due to competitive effects or due to the production of compounds that inhibit their development and proliferation (10). An additional function of these products seems to be interference in mucosa immunity by modulating $\operatorname{IgA}$ synthesis and mucus production, or alterations in antiinflammatory regulation (20).

There is increasing evidence that probiotics have therapeutic actions, especially in disturbances involving the

*Corresponding Author. Mailing address: Instituto Básico de Biociências - Universidade de Taubaté - Taubaté, Brazil.; Tel.: +55 12 3629-7909/ +55 12 9781 3344.; Email: ag lima86@ hotmail.com 
gastrointestinal (5), genitourinary (17) and immunological systems (16). Hickson et al. (8) showed that the consumption of a probiotic drink containing Lactobacillus casei, L. bulgaricus and Streptococcus thermophilus was able to reduce the incidence of diarrheas associated with antibiotics use and caused by Clostridium difficile. Larsson et al. (14) observed that lactobacilli used as a supplement during clindamycin treatment in patients with bacterial vaginosis significantly reduced the recurrence rate and extended the period of recurrence.

Disequilibrium in microbiota can favor the growth of opportunist microorganisms and the development of pathologies, such as candidosis, an infection caused by yeasts of the Candida genus $(13,18)$. These microorganisms can be identified in the oral cavity of 30 to $60 \%$ of healthy individuals and the role of secretory antibodies in the prevention of their establishment and proliferation is controversial $(9,19)$.

Biasoli and Magaró (2) observed a reduction in the adhesion of Candida albicans to oral epithelial cells with the introduction of L. casei and L. acidophilus in vitro. Hatakka et al. (7) studied the effect of a cheese enriched with probiotic bacteria on Candida prevalence in the oral cavity of elderly individuals and observed a $32 \%$ reduction in prevalence. In this work, the influence of probiotics consumption on the levels of anti-Candida $\operatorname{IgA}$ and on the presence of these yeasts in the oral cavity of healthy young individuals was evaluated.

\section{MATERIAL AND METHODS}

After the approval of this project by the local Ethics in Research Committee, healthy young individuals were selected, excluding those who had used antibiotics for a period of three months, who were smokers or wearers of prosthesis or orthodontic devices. All the participants were fully informed concerning the objectives and methodology of the study and provided a written free, informed term of consent.
Initially, 111 individual were analyzed and samples of their saliva were collected without stimulation. Those individuals who presented Candida yeasts in the oral cavity were selected and if the microorganisms were identified again one month later, they were instructed to use the probiotics Yakult LB (Lactobacillus casei and Bifidobacterium breve, $2 \times 10^{7}$ to $10^{9}$ and $5 \times 10^{7}$ to $10^{9}$ $\mathrm{UFC} / \mathrm{mL}$, respectively) daily for 20 days. After this period, another saliva sample was collected from each of the 26 participants.

All the samples were plated in duplicate in Saboraud Dextrose Agar (OXOID, Lawrence, KS, USA), to which $1 \mathrm{mg} / \mathrm{mL}$ of chloramphenicol was added (INLAB, São Paulo, SP, Brazil), followed by incubation at $37^{\circ} \mathrm{C}$ for 48 hours and at room temperature for five days. Next, the number of colony forming units per $\mathrm{mL}$ of saliva was determined $(\mathrm{CFU} / \mathrm{mL})$. Suggestive colonies from each plate were confirmed by smear tests stained by the Gram technique. Next, the Candida species were identified by phenotypic (germinative tube formation and chlamydoconidia production) and biochemistry tests (fermentation and assimilation of carbohydrates and urase test).

The levels of anti-Candida $\operatorname{IgA}$ were also analyzed using the ELISA technique. Sensitization of ELISA plates was performed using surface antigens from Candida cells, prepared as described by Koga-Ito et al. (13). The plates were then incubated with diluted saliva (1: 10), followed by an anti-human $\operatorname{IgA}$ labeled with horseradish peroxidase. The reaction was developed with orthophenylenediamine and $\mathrm{H}_{2} \mathrm{O}_{2}$ as substrate. Absorbance was measured at $450 \mathrm{~nm}$.

Data regarding the $\mathrm{CFU} / \mathrm{mL}$ counts and IgA antiCandida levels, before and after the use of probiotics, were compared using the Student $t$ test, with a level of significance of $\mathrm{p}<0.05(5 \%)$.

\section{RESULTS}

The results showed a significant reduction in the log mean of CFU/mL counts after the use of probiotics of $65 \%$ (Figure 1). A reduction of $46 \%$ in the prevalence of Candida 
Santos, A.L. et al.

in oral cavity was also observed; i.e., out of the 26 individuals selected, Candida was no longer identified in 12.

Among the identified species of Candida, $98 \%$ were $C$. albicans and $2 \%$ C. tropicalis, both before and after probiotics use, showing that the product did not alter the species profile.

Immunological analysis showed a significant reduction in the levels of anti-Candida IgA (Figure 2).

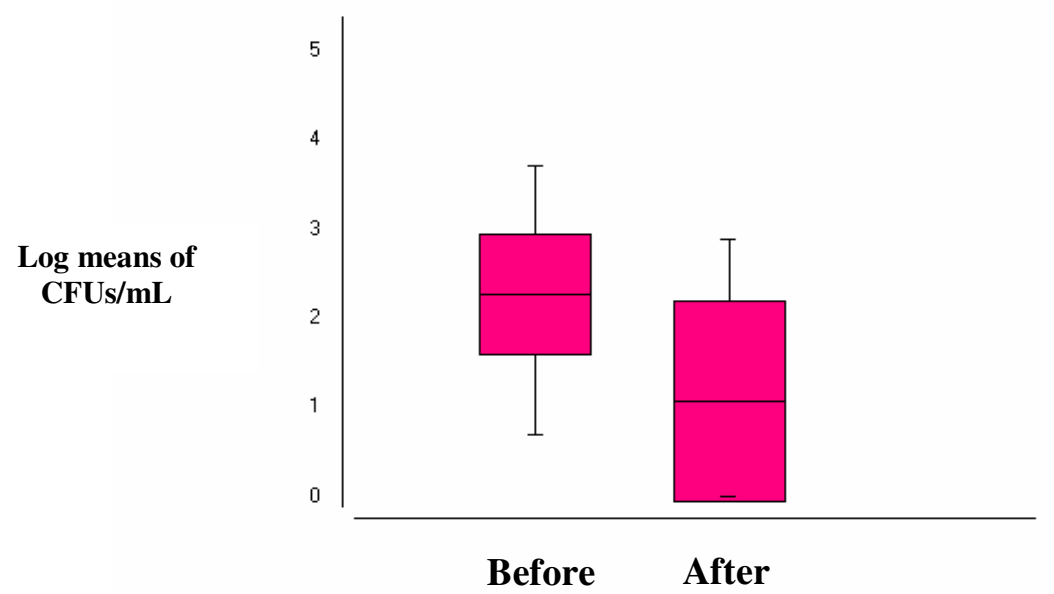

Figure 1. Log means of CFUs/mL of Candida before and after probiotics use; Student $\mathrm{t}$ test, $\mathrm{p}=0.0000$.

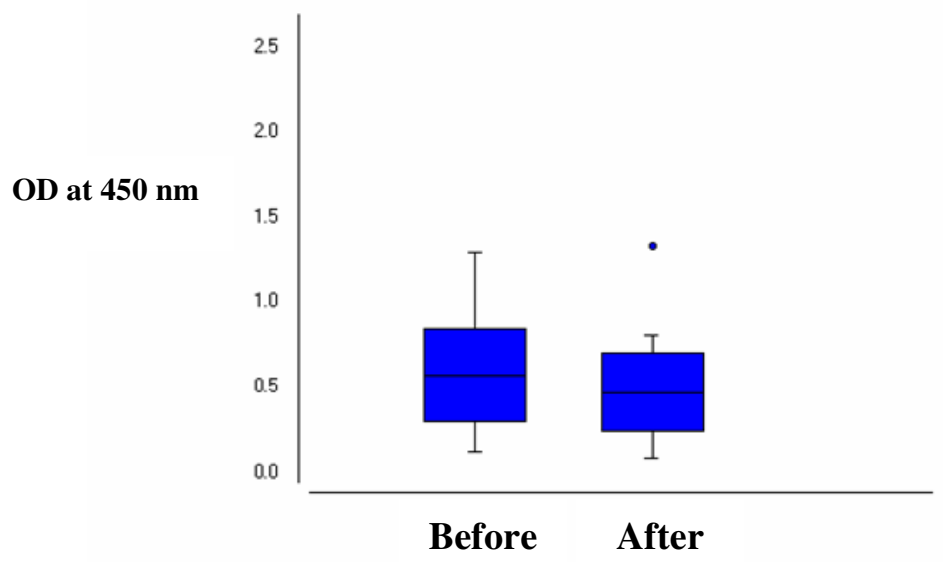

Figure 2. Means of optical density (OD) corresponding to IgA anti-Candida saliva levels before and after probiotics use; Student t test, $\mathrm{p}=0.028$.

\section{DISCUSSION}

Analysis of the results showed that the probiotics significantly influenced the amount of Candida identified in the oral cavity, since a reduction in $\mathrm{CFU} / \mathrm{mL}$ counts was observed after probiotics use. A similar reduction in Candida levels after probiotics consumption was observed by Elahi et al. (6), although in rats with oral candidosis. In the present work, a reduction in the prevalence of Candida was also observed. Hatakka et al. (7) previously reported that cheese enriched with probiotic bacteria was able to reduce the prevalence of Candida in the oral cavity of elderly individuals. However, the reduction observed by the authors was lower, approximately $32 \%$. The difference in prevalence 
reduction can be explained by the populations studied, since elderly individuals show a greater predisposition for yeast adherence, due to the use of dental prostheses and other factors.

The most frequently isolated species of Candida before and after the use of the probiotics was $C$. albicans. In fact, $C$. albicans is the species most frequently identified in the oral cavity and the species most often reported in relation to pathological situations.

The reduction in the amount and prevalence of Candida in the oral cavity after the probiotics consumption could have occurred due to different mechanisms of action. According to Boirivant and Strober (3), probiotics can improve the defense function of epithelial cells by the induction of cytokine secretion and the production of immunoglobulins and antimicrobial substances. According to Matsuzaki et al. (15), certain probiotic bacteria have the potential to increase and modify the immune function of the host through the regulation of defense cells. However, the present results revealed that after the period of probiotics use, a significant reduction in the levels of specific IgA was observed.

Controversial results regarding the correlation of Candida and anti-Candida $\operatorname{IgA}$ levels have been reported. Jeganathan et al. (11) observed that patients with candidosis showed higher levels of anti-Candida $\operatorname{IgA}$ compared to the control group (absence of candidosis). Kantardjiev and Popova (12) reported that the saliva samples of patients with denture stomatitis, mainly associated with Candida, showed higher titers of anti-Candida antibodies compared to controls. Barousse et al. (1) observed no significant differences in total and Candida specific $\operatorname{IgA}$ and $\operatorname{IgG}$ concentrations in individuals with and without yeast colonization. In contrast, Vudhichamnong et al. (19) and Holmes et al. (9) observed an inverse relation between Candida $\mathrm{CFU} / \mathrm{mL}$ counts and specific levels of $\operatorname{IgA}$ against this microorganism; i.e., the lower the values of $\mathrm{CFU} / \mathrm{mL}$ counts, the higher the levels of anti-Candida $\operatorname{Ig}$ A.

Since some individuals in this study, after probiotics use, did not present the yeast or showed diminished amounts in the oral cavity, it is likely that a reduction in antigenic stimulation occurred with a consequent reduction in the production of secretory antibodies.

It cannot be inferred that Candida elimination occurred due to secretory immunological stimulation mediated by probiotics use. The results obtained indicate a mechanism of competition and interference in the adhesion of Candida to epithelial cells mediated by this product. Given the fact that antibody levels were not monitored throughout the experimental period, we can not negate the hypothesis of an initial stimulation, contributing to the elimination of the microorganism, and a posterior reduction of the response to normal or lower levels, as detected in the research.

It is clear in the literature that $\operatorname{IgA}$ plays a role in the defense of the human body against yeasts of the Candida genus; however, scarce data is available regarding their role in association with probiotics supplementation. Further studies involving the adherence of probiotics to the epithelial cells of the oral mucosa and specific studies concerning probiotics and Candida competition are required to definitively elucidate the effects observed.

\section{REFERENCES}

1. Barousse, M.M.; Van Der Pol, B.J.; Fortenberry D.; Orr, D.; Fidel, P.L. JR. (2004). Vaginal yeast colonisation, prevalence of vaginitis, and associated local immunity in adolescents. Sex. Transm. Infect. 80(1), 48-53.

2. Biasoli, M.S.; Magaró, H.M. (2003). In vitro of carbohydrates and enteric bacteria on adherence of Candida albicans. Rev. Iberoam. Micol. 20(4), 160-163.

3. Boirivant, M.; Strober, W. (2007). The mechanism of action of probiotics Curr. Opin. Gastroenterol. 23(6), 679- 692.

4. Fuller, R. (1989). Probiotics in man and animals. J. Appl. Bacteriol. 66(5), 365-78.

5. Gismondo, M.R.; Drago L.; Lombardi, A. (1999). Review of probiotics available to modify intestinal microflora. Int. J. Antimicrob. Agents 12(4), 287-292. Apud: Mombelli, B.; Gismondo, M.R. (2000). The use of probiotics in medical practice. Int. J. Antimicrob. Agents. 16(4), 531536.

6. Elahi, S.; Pang, G.; Ashman, R.; Clancy, R. (2005). Enhanced clearance of Candida albicans from the oral cavities of mice following 
Santos, A.L. et al.

oral administration of Lactobacillus acidophilus. Clin. Exp. Immun. 141, 29-36.

7. Hatakka, K.; Ahola, A.J.; Yli-Knuuttila, H.; Richardson, M.; Poussa, T.; Meurman, J.H.; Korpela, R. (2007). Probiotics reduce the prevalence of oral Candida in the Elderly - a randomized controlled Trial. J. Dent. Res. 86, 125-130.

8. Hickson, M.; D’Souza, A.L.; Muthu, N.; Rogers, T.R.; Want, S.; Raikumar, C.; Bulpitt, C.J. (2007). Use of probiotic Lactobacillus preparation to prevent diarrhoea associated with antibiotics: randomised double blind placebo controlled trial. BMJ. 335(7610), 80.

9. Holmes, A.R.; Bandara, B.M.K.; Cannon, R.D. (2002). Saliva promotes C. albicans adherence to human epithelial cells. J. Dent. Res. 81(1), 2832 .

10. Jacobsen, C.N.; Nielsen, V.R.; Hayford, A.E.; Moller, P.L.; Michael Sen, K.F.; Paerregaard, A.; Sandström, B.; Tvede, M.; Jacobsen, M. (1999). Screening of probiotic activities of forty-seven strains of Lactobacillus spp. by in vitro techniques and evaluation of the colonization ability of five selected strais in humans. Appl. Environ. Microbiol. 11(65), 4949-56.

11. Jeganathan, S.; Ufomata, D.; Hobkirk, J.A.; Ivanyi, L. (1987). Immunoglobulin A1 and A2 subclass of salivary antibodies to Candida albicans in patients with oral candidosis. Clin Exp Immunol. 70(2), 316-21.

12. Kantardjiev, T.V.; Popova, E.V. (2002). Anti-Candida antibodies in serum and saliva of patients with denture stomatitis. Folia Med (Plovdiv). 44(4), 39-44.

13. Koga-Ito, C.Y.; Martins, C.A.P.; Jorge, A.O.C. (2006). Estudo do Gênero Candida. In: Jorge, A.O.C. ( $1^{\mathrm{a}}$ ed) Princípios de Microbiologia e Imunologia. Editora Santos, São Paulo, Brazil.

14. Larsson P.G.; Stray-Pedersen, B.; Ryttig, K.R.; Larsen, S. (2008). Human lactobacilli as supplementation of clindamycin to patients with bacterial vaginosis reduce the recurrence rate; a 6-month, double-blind, randomized, placebo-controlled study. BMC Womens Health. 15, 8-3.

15. Matsuzaki, T.; Takagi, A.; Ikimura, H.; Matsuguchi, T.; Yokokura, T. (2007). Intestinal Microflora: probiotics and autoimmunity. J. Nutr. 137(3 suppl. 2), 798S-802S.

16. Pelto, L.; Isolauri, E.; Lilius, E.; Nuutila, Salmimen, S. (1998). Probiotic bacteria down-regulate the milk induced inflammatory response in milk hypersensitive subjects but have an immunostimulatory effect in healthy subjects. Clin. Exper. Allergy. 28(12):1474-1479.

17. Velraeds, M.M.; Van Der Mei, H.C.; Reid, G.; Busscher, H.J. (1996). Inhibition of initial adhesion of uropathogenic Enterococcus faecalis by biosurfactants from Lactobacillus isolates. Appl. Env. Microbiol. 62(2), 1958-63. Apud: MombellI, B.; Gismondo, M.R. The use of probiotics in medical practice. (2000). Int. J. Antimicrob. Agents. 16(4), 531-536.

18. Vieira, J.D.G.; Ribeiro, E.L.; Campos, C.C.; Pimenta, F.C.; Toledo, O.A; Nagato, G.M.; Souza, N.A.; Ferreira, W.M.; Cardoso, C.G.; Dias, S.M.S; Araújo, C.A; Zatta, D.T.; Santos, J.S. (2005). Candida albicans isoladas da cavidade bucal de crianças com síndrome de Down: ocorrência e inibição do crescimento por Streptomyces sp Rev. Soc. Bras. Med. Trop. 38(5), 383-86.

19. Vudhichamnong, K.; Walker, D.M.; Ryley, H.C. (1982). The effect of secretory immunoglobulin A on the in-vitro adherence of the yeast $C$. albicans to human oral epithelial cells. Arch. Oral. Biol. 27(8), 617-21.

20. Wehkamp, J.; Harder, J.; Wehkamp, K.; Wehkamp-Von Meissner, B.; Schlee, M.; Enders, C.; Sonnenborn, U.; Nuding, S.; Bengmark, S.; Fellermann, K.; Schröder, J.M.; Sange, E.F. (2004). NF- ${ }_{\mathrm{K}} \mathrm{B}-$ and AP-1mediated induction of human beta defensin-2 in intestinal epithelial cells by Escherichia coli Nissle 1917: a novel effect of a probiotic bacterium. Infect. Immun. 10(72), 5750-58. 